\title{
Rapid progressive dementia associated with neurosyphilis
}

Demência rapidamente progressiva associada à neurossífilis

Antonio Lucio Teixeira ${ }^{1}$, José Augusto Malheiros ${ }^{1}$ and José Roberto Lambertucci ${ }^{2}$

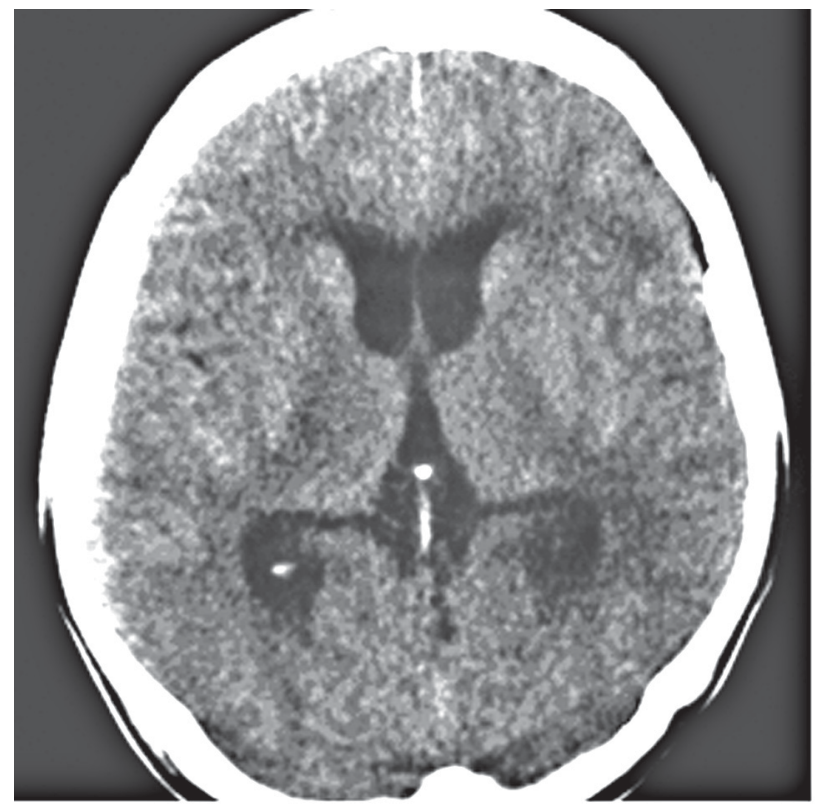

A

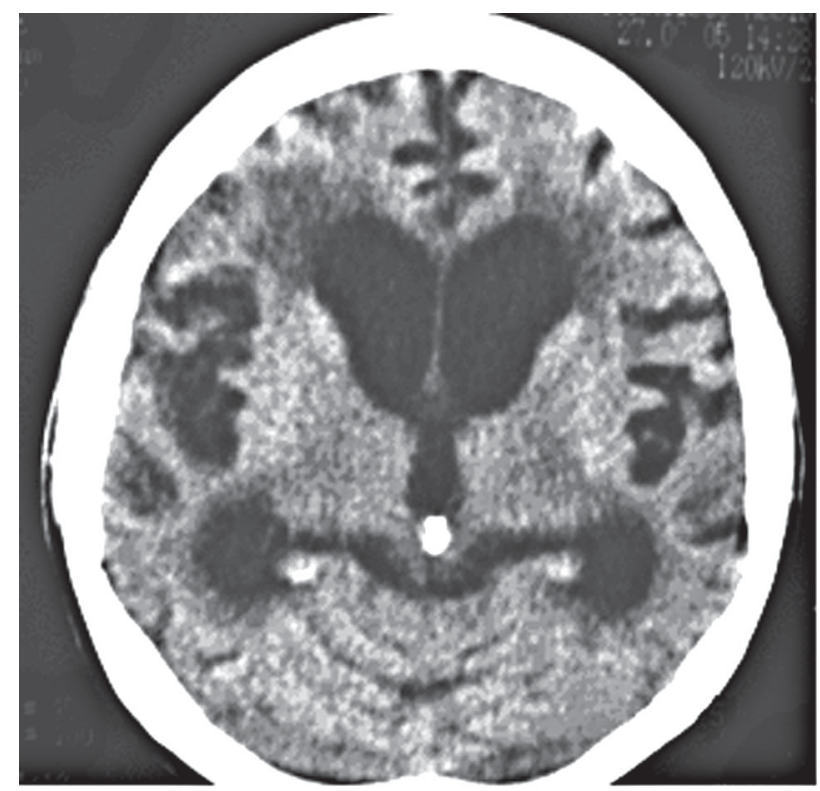

B

1.Serviço de Neurologia do Hospital das Clínicas da Universidade Federal de Minas Gerais, Belo Horizonte, MG. 2. Serviço de Doenças Infecciosas da Faculdade de Medicina da Universidade Federal de Minas Gerais, Belo Horizonte, MG.

Address to: Prof. José Roberto Lambertucci. Serviço de Doença Infecciosas/Faculdade de Medicina/UFMG. Av. Alfredo Balena 190, 30130-100 Belo Horizonte, MG.

e-mail: lamber@uai.com.br

Recebido para publicação em 10/7/2006

Aceito em 28/7/2006 
A 44-year-old man was admitted to hospital to investigate a dementia initiated in the previous year. Lately, he became bedridden and dependent on caregivers. The clinical onset was characterized by psychosis with visual hallucinations, paranoid delusions and hostility, and he was treated with haloperidol. At this point, a computerized tomography (CT) of the brain showed no alteration (Figure A). He evolved with progressive infantile behavior. The neurological examination revealed an alert patient with mutism, rigidity, hypereflexia, bilateral Babinski sign and other cortical release signs, such as glabelar, suckling, palm-mentonian and grasping reflexes. He was submitted to a careful laboratory workup to exclude secondary causes of dementia, including hemogram, ionogram, renal, hepatic and thyroid function tests, measurement of B12 and folic acid, and serological studies for syphilis and HIV. A serum positive VDRL test (1:128) was confirmed by an FTA-abs test. A new CT was performed and revealed diffuse cerebral atrophy (Figure $B$ - notice the dilation of ventricles). The cerebrospinal fluid examination revealed increased proteins $(63 \mathrm{mg} / \mathrm{dl})$ and cells $\left(8 \mathrm{cells} / \mathrm{mm}^{3}\right.$; $93 \%$ mononuclear cells). He was started on sodium G penicillin ( 24 million units per day IV for 21 days), without improvement.

0 paciente, de 44 anos, foi admitido ao hospital para investigação de quadro de demência de um ano de evolução; ele encontrava-se restrito ao leito e dependente de cuidadores. As manifestações neurológicas iniciais constavam de sintomas psicóticos, caracterizados por alucinações visuais, delírios paranóides e agressividade, e decidiu-se pelo tratamento com haloperidol. Nessa época, a tomografia computadorizada (TC) do crânio não mostrou alterações significativas (Figura A). A doença evoluiu com infantilização progressiva do paciente. 0 exame neurológico revelou um indivíduo alerta, com mutismo, rigidez e hiperreflexia globais, sinal de Babinski bilateral, e sinais de liberação cortical, como reflexos glabelar, de sucção, palmo-mentoniano e grasping. Submeteu-se, então, à extensa propedêutica laboratorial para investigar causas secundárias de demência, incluindo hemograma, ionograma, provas de função renal, hepática e tireoidiana, dosagem de vitamina B12 e ácido fólico, sorologia para sífilis e HIV. O VDRL no soro mostrou-se positivo na diluição de 1:128 e o FTA-abs confirmou a presença da infecção pelo Treponema pallidum. A nova TC de crânio evidenciou marcada atrofia cerebral difusa (Figura B - note a dilatação dos ventrículos). 0 exame do líquor mostrou aumento de proteínas (63mg/dl) e de células (8 células/ $/ \mathrm{mm}^{3}, 93 \%$ mononucleares). Ele recebeu tratamento com penicilina $\mathrm{G}$ cristalina, na dosagem de 24 milhões de unidades por dia durante 21 dias, sem melhora.

\section{REFERENCES}

1. O'Donnell JA, Emery CL. Neurosyphilis: a current review. Current Infectious Disease Report 7: 277-284, 2005.

2. Passoni, LFC, Menezes, JA, Ribeiro SR, Sampaio ECO. Lues maligna em um paciente com infecção pelo HIV. Revista da Sociedade Brasileira de Medicina Tropical 38: 181-184, 2005.

3. Takada LT, Caramelli P, Radanovic M, Anghinah R, Hartmann AP, Guariglia CC, Bahia VS, Nitrini R. Prevalence of potentially reversible dementias in a dementia outpatient clinic of a tertiary university-affiliated hospital in Brazil. Arquivos de Neuropsiquiatria 61: 925-929, 2003. 